\title{
Stroke due to calcific embolism after cardiac procedures
}

Acidente vascular decorrente de embolismo calcificado após procedimentos cardiológicos

Farrukh S. Chaudhry, Daniel Vela-Duarte, José Biller

We evaluated two patients with calcific brain embolism².

Following trans-septal cardiac catheterization, an 84-year-old woman with coronary artery disease and prior
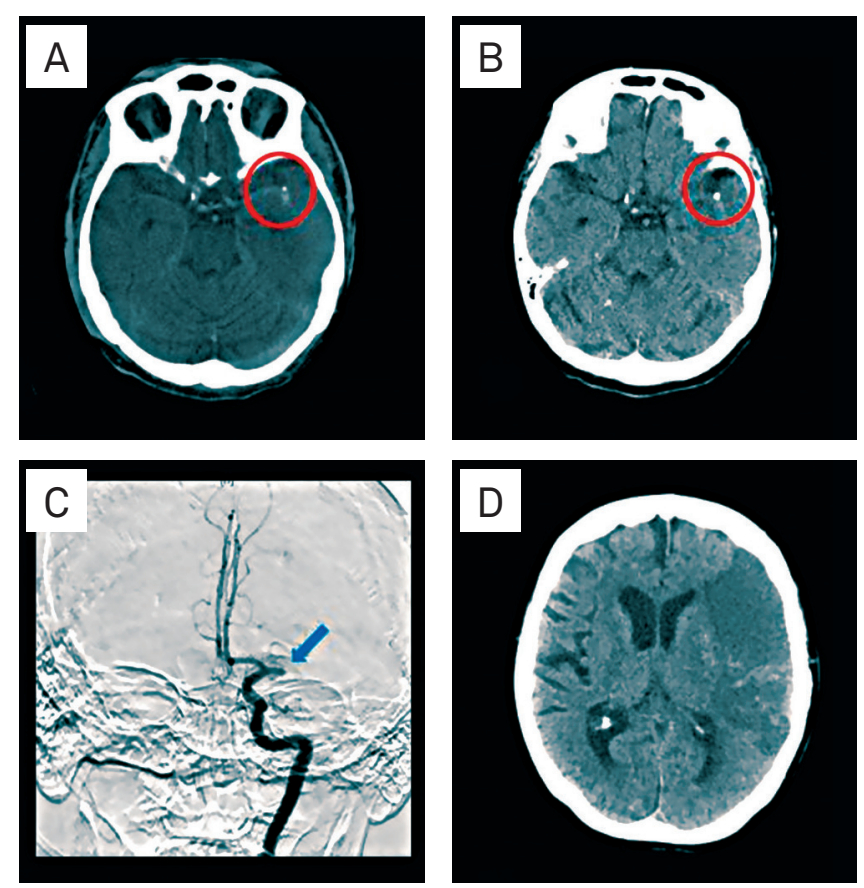

Fig 1. Computed tomography shows calcific embolus (circle) of the left middle cerebral artery (A), left middle cerebral artery calcific embolus three days after index event (B), and left internal carotid artery (ICA) injection shows occlusion (arrow) of M1 segment of the left middle cerebral artery (C). Computed tomography shows extensive left frontal-parietal area of hypoattenuation involving the superior division of the left middle cerebral artery. mitral valve annuloplasty and bioprosthetic aortic valve replacement, had aphasia and right hemiparesis. Computed tomography (CT) showed a calcific embolus of the left middle cerebral artery (MCA) (Fig 1).

Following coronary artery bypass graft, aortic and mitral valve replacement, and patent foramen ovale closure, a 51-year-old man, had left hemiplegia and right gaze deviation. CT showed calcific embolus involving the stem of the right MCA (Fig 2).
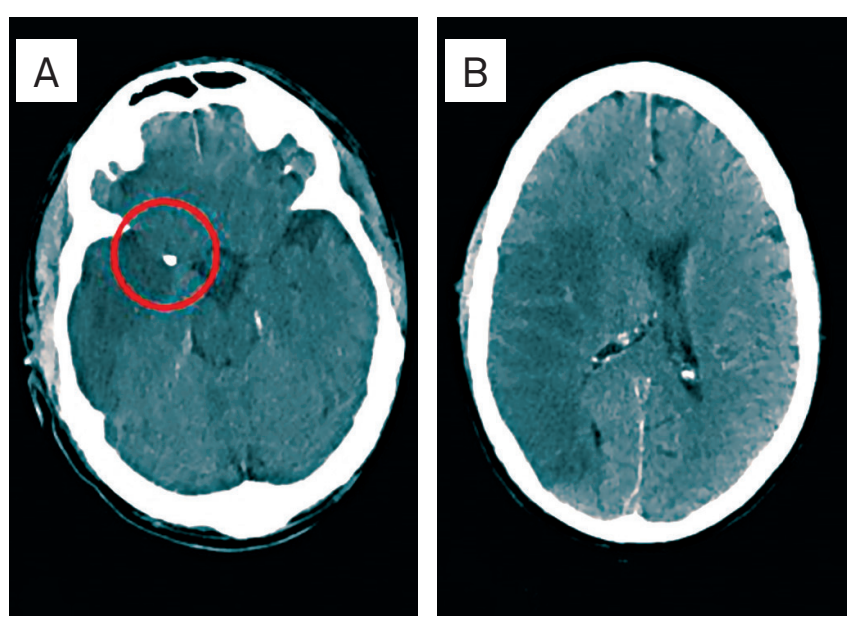

Fig 2. Computed tomography shows calcific embolus (circle) of the M1 segment of the right middle cerebral artery (A); extensive right frontal-parietal area of hypoattenuation involving the territory of the right middle cerebral artery (B).

\section{References}

\footnotetext{
1. Kirk GR, Johnson JK. Computed tomography detection of a cerebral calcific embolus following coronary catherization. J Neuroimaging $1994 ; 4 ; 241-242$.
} 